\title{
Prevalence and complications of obesity and overweight among Algerian adolescents
}

\author{
Karima Benmohammed $^{\mathrm{a}, *}$, Paul Valensi ${ }^{\mathrm{b}}$, Minh Tuan Nguyen ${ }^{\mathrm{b}}$, Farah Benmohammed $^{\mathrm{c}}$ \\ and Alkassem Lezzar ${ }^{\mathrm{a}}$ \\ ${ }^{a}$ Department of Endocrinology and Diabetology, Benbadis University Hospital, Constantine \\ University, Algeria \\ ${ }^{\mathrm{b}}$ Department of Endocrinology Diabetology Nutrition, Jean Verdier Hospital, AP-HP, Paris \\ Nord University, CRNH-IdF, CINFO, Bondy, France \\ ${ }^{\mathrm{c}}$ Hôpital Santa Cabrini Ospedal, Montreal University, Montréal, Canada
}

Received 20 July 2017

Accepted 15 October 2017

\begin{abstract}
.
OBJECTIVE: To determine the prevalence of overweight and obesity in Algerian adolescents and investigate the associated cardiometabolic complications.

METHODS: The study was conducted in the city of Constantine (Algeria). The population included 1100 schooled adolescent, aged 12-18 years, randomly selected. All had anthropometric measurements, and 989 had blood tests. The BMI was calculated and the prevalence of overweight and obesity was determined using the International Obesity Task Force reference values.

RESULTS: $179(16.3 \%)$ adolescents were overweight including 74 boys (13.8\%) and 105 girls (18.6\%), 51 (4.6\%) adolescents were obese including $25(4.6 \%)$ boys vs $26(4.6 \%)$ girls $(p=0.09)$. Overweight and obese adolescents had higher systolic blood pressure/diastolic blood pressure $(p=0.001 / p<0.0001)$ and abnormal blood lipid levels. Furthermore, the HOMA index was higher in overweight and obese adolescents $(p<0.0001)$.

CONCLUSION: These findings show a high prevalence of overweight and obesity in a population of Algerian adolescents leading to significant cardiometabolic abnormalities.
\end{abstract}

Keywords: Overweight, obesity, adolescents, cardiometabolic complications, insulin resistance, Algeria

\section{Introduction}

Obesity and overweight are among the leading health issues in both developed and developing countries worldwide. The prevalence of obesity is now reaching epidemic levels. For instance, in 2014, more than 1.9 billion adults (39\% of the world population) were overweight including over 600 million adults (13\% of the

\footnotetext{
*Corresponding author: Dr Karima Benmohammed, MD, MSC, Department of Endocrinology, Centre Hospitalier Universitaire de Constantine, Université de Constantine, 25000 Algeria. E-mail: benmohamsana@yahoo.fr.
} 
world population) considered to be obese. In addition to that, it is estimated that 41 million children under the age of 5 years are overweight, of whom approximately 31 million are from developing countries [1]. In 2013, an estimated $23.8 \%$ of boys and $22.6 \%$ of girls from developed countries were overweight or obese compared to only $12.9 \%$ of boys and $13.4 \%$ of girls who were overweight or obese in developing countries [2]. However, the prevalence of child obesity is increasing in developing countries due to newly adopted westernised lifestyle habits such as the consumption of high energy and density foods and having a sedentary lifestyle which leads to negative health and socioeconomic outcomes [2-6].

Similarly as in adulthood, obesity can have several metabolic and cardiovascular complications in childhood [7-14]. These complications are mainly the consequence of insulin resistance (IR) and hyperinsulinemia, which are the most common metabolic abnormalities in obesity $[9,12,15]$. Furthermore, obese children and adolescents are at risk of remaining obese at adulthood and thus, developing future cardiometabolic diseases [9, 13, 15-17].

Finally, the financial burden of these complications is significant. In a recent German study, lifetime excess costs were estimated to be higher among adults who were overweight or obese during their childhood. The study showed that for 18-years old women (men) who have been overweight or obese during their childhood (from age 3 to 17 years old), undiscounted lifetime excess costs are estimated at $€ 19,479(€ 14,524)$ [18].

The aim of this study was to estimate the prevalence of overweight and obesity in Algerian adolescents and to investigate their association with cardiometabolic abnormalities.

\section{Methods}

The study period was from March 10th, 2007 to April 28th, 2007. The studied population included 1100 schooled adolescents, aged 12 to 18 years old, from the Constantine schools in Algeria.

\subsection{Sample selection}

Adolescents were randomly selected at three distinct stages using a random survey. The stages included the school (high school, middle school), the classroom and then the students. The schools were classified according to their institution numbers (provided by the city's education board, from 1 to 26 for high schools and from 1 to 56 for middle schools). For the first selection stage, 13 high schools and 14 middle schools were randomly selected with a sampling fraction of 0.5 and 0.25 , respectively. A similar method was used to select the classrooms and students according to lists, including fixing a sampling rate. A total of 1100 adolescents [537 boys (49\%) and 563 girls (51\%)] aged 12 to 18 years were selected. All had a physical examination, and blood tests were performed in all but 111 students who were afraid of needles or absent on the day of blood sampling.

\subsection{Survey, anthropometric and blood pressure measurements}

All adolescents completed a non anonymous self-administered questionnaire and had anthropometric measurements.

The survey included information about civil status, personal and family medical history and lifestyle habits especially the consumption of sweetened snacks and the practice of regular physical activity (defined by at least 60 minutes per day of moderate to intense physical exercise, 5 days a week) $[14,19]$.

Anthropometric measurements were conducted in physical examination rooms by general practitioners (GPs) and school doctors. Measurements included the height (without shoes) to the nearest $0.1 \mathrm{~cm}$ using a portable Stadimeter (Leicester Height Measure, Seca Limited, Birmingham, UK), and the weight (wearing light indoor clothing and no shoes) to the nearest $0.1 \mathrm{~kg}$ using standard scales (Seca Ltd). BMI was then calculated according to standard formula (weight/height ${ }^{2}, \mathrm{~kg} / \mathrm{m}^{2}$ ). We used the definition of overweight and obesity in children and adolescents according to The International Obesity Task Force (IOTF) standards [20]. Waist circumference was 
measured in the standing position, to the nearest $0.1 \mathrm{~cm}$, using a special measuring tape with an automatic roll-up, placed mid-distance between the costal edge and the iliac crest [21].

Blood pressure (BP) was measured in accordance with international guidelines [22], at three different times, with a sphygmomanometer and an adapted cuff, after 5 minutes of rest and in a sitting position. The mean value was then calculated.

Detailed methods were given in a previous paper [23].

\subsection{Blood analysis}

All fasting blood tests (12 hours) were performed between 8 and 9 am and immediately transferred to the laboratory. Blood analysis included: fasting glucose level, triglycerides, total cholesterol, HDLc, using enzymatic methods with an automatic analyser (ADVIA IMS system). LDLc was then calculated according to the Friedwald formula.

Reference values for hyperglycemia and dyslipidemia in children and adolescents are based on International Diabetes Federation (IDF) criteria and guidelines from the North American National Cholesterol Education Program $[24,25]$.

Furthermore, insulin was measured by the automatic analyser AxSym using enzymatic methods (microparticule enzyme immuno assay: MEIA). The Homeostasis Model Assessment (HOMA) for estimating insulin resistance, was calculated by the following formula: [Fasting insulin $(\mu \mathrm{U} / \mathrm{mL}) \times$ Fasting plasma glucose $(\mathrm{g} / \mathrm{l}) \times 5.5] / 22.5$ [26]. However, there are no definite cut-off points for HOMA values to define insulin resistance, so we chose the value 3 , the average reported in several publications [27-30].

\subsection{Statistical analysis}

Data analysis was performed using SPSS software (version 15.0). Results were expressed as percentages and mean \pm SD. Comparisons between groups used ANOVA for continuous variables and $\chi^{2}$ and Fisher exact tests for categorical variables. The statistical significance threshold used for this study was $P<0.05$.

\subsection{Ethical considerations}

The study was approved by the Constantine health authorities and the institutional review board. An informed consent was signed by parents or legal guardians of the adolescents before participating in this research.

\section{Results}

The mean age of adolescents was $15.5 \pm 1.8$ years. 179 (16.3\% of the studied population) were overweight (74 boys and 105 girls) and 51 (4.6\%) were obese ( 25 boys and 26 girls). There was no statistically significant difference according to gender (13.8\% of boys, $18.6 \%$ of girls were overweight and $4.6 \%$ of boys, $4.6 \%$ of girls were obese $(p=0.09)$.

There was a statistically significant correlation between overweight classification and age: the largest frequency of overweight was observed in adolescents aged 15 and 16 years old, while obesity was more frequent between 12 and 15 years $(p=0.036)$.

A family history of excess weight was present in $40.2 \%$ of overweight and $68.6 \%$ of obese adolescents, compared to only $24.9 \%$ among normal weight adolescents $(p<0.0001) .73 .8 \%$ of adolescents with normal weight reported consuming sweet snacks compared to only $68.7 \%$ of overweight and $56.9 \%$ of obese adolescents $(p=0.009)$. Furthermore, $60.9 \%$ of overweight and $74.5 \%$ of obese adolescents declared practicing regular physical compared to only $63.9 \%$ of normal weight adolescents $(p<0.0001)$. 
Systolic blood pressure (SBP) and Diastolic blood pressure (DBP) were more elevated in both overweight and obese adolescents compared to adolescents with normal weight ( $p=0.001$ and $<0,0001$ respectively).

The percentage of adolescents with fasting plasma glucose levels $\geq 1 \mathrm{~g} / 1$ was higher among both normal weight $(8.9 \%)$ and overweight groups $(10 \%)(p=0.21)$. The percentage of adolescents with plasma triglyceride levels $\geq 1.1 \mathrm{~g} / \mathrm{l}$ or HDLc $\leq 0.4 \mathrm{~g} / \mathrm{l}$ was higher in overweight groups $(19.7 \%, 17.3 \%)$ compared to normal weight $(9.2 \%, 7.8 \%)$ and obese groups $(10.2 \%, 8.3 \%)(p=0.001)$. Overweight adolescents had also higher total cholesterol and LDLc levels compared to other groups. Finally, both overweight and obese adolescents had higher mean HOMA index and insulin resistance defined by a HOMA index $\geq 3$, compared to normal weight groups (HOMA: $3.41 \pm 2.03$ in obese, $2.61 \pm 1.21$ in overweight, $1.84 \pm 0.92$ in normal weight adolescents, $p<0.0001 ; 41.7 \%$ of obese, $30 \%$ of overweight, and $12.4 \%$ of normal weight adolescents had HOMA $\geq 3, p=0.012$ ) (Table 1).

\section{Discussion}

Obesity is one of the leading global healthcare issues in the 21st century. The obesity epidemic also affects children and adolescent populations with the increasing prevalence of overweight and obesity in these age groups [2]. Multiples studies on preschool children have demonstrated an increase in the prevalence of obesity especially in Latin America, the Caribbean, the Middle East and North African countries compared to the United States [4]. Also, the prevalence of overweight children is higher in urban areas compared to rural environments. Is has also been demonstrated that the prevalence of overweight children is higher in female populations and within private schools compared to public schools [4]. Furthermore, the ethnic background is an important determinant of prevalence of adolescent and child obesity [31-33].

This study included 1100 adolescents from the city of Constantine, of whom $16.3 \%$ were overweight and $4.6 \%$ obese. These proportions are comparable to the estimated percentages of obesity and overweight adolescents from the Maghreb and North African regions. However, these proportions are lower than estimations in populations from Gulf countries, the United States and Europe (especially Mediterranean European countries, and the United Kingdom) [3-5, 7, 31, 34-38]. A study in the Netherlands estimated the prevalence of overweight and obesity in Moroccan descendants aged under 21 years old, according to IOTF criteria, at $15.8 \%$ and $3.1 \%$ respectively in boys compared to $24.5 \%$ and $5.4 \%$ respectively in girls [36]. In France, a study showed that the prevalence of obesity was higher in French born children with Maghrebi origins, especially in girls [39]. In Australia, a study conducted on a Sidney multiethnic population of 3645 children aged between 5 and 12 years old showed that children of Mediterranean descendants had higher BMIs, followed by children with North European origins and those from mixed ethnics (Caucasian and Asian). The study also showed that Asian children had the lowest calculated BMI levels [40]. In the USA, while the overall rate of child and adolescent obesity had stabilized over the last decade, obesity rates continue to increase in certain populations, such as African American girls and Hispanic boys. These ethnical differences in the prevalence of obesity are likely due to both genetic and non-genetic factors, for example: socioeconomic level, the consumption of sweetened beverages and fast food, and having a television in the bedroom [31]. In fact, the rapid rise in the prevalence of obesity in these populations demonstrates the influence of environmental factors $[3,4,10]$.

The present study shows that obese and overweight adolescents have family history of obesity, practice more physical activities and consume lower amounts of sweetened snacks. It also suggests that the influence of family history and genetic factors is stronger than environmental factors for the development of obesity. In fact family history of obesity may result from unhealthy dietary habits, and we must consider the likelihood of some underestimation of unhealthy habits with misdeclarations issued by the obese adolescents (as the surveys were not anonymous). However the possibility of sudden changes in their lifestyle habits due to a better awareness of their health risks is not excluded.

Additionally, we were surprised to observe the widespread of certain unhealthy lifestyle habits in the studied adolescents of whom $73.8 \%$ of normal weight patients consumed regular sweetened snacks, which is an important 
Table 1

Clinical and biological characteristics of overweight and obese adolescents using International Obesity Task Force references.

Mean $\pm \mathrm{DS} ; \mathrm{N}(\%)$

\begin{tabular}{|c|c|c|c|c|c|}
\hline Parameter & Total $^{*}$ & Normal weight & Overweight & Obese & $\mathrm{P}$ \\
\hline Number & 1100 & 870 & 179 & 51 & \\
\hline \multicolumn{6}{|l|}{ Age (yrs) } \\
\hline 12 & 123 & $89(10.2 \%)$ & $25(14 \%)$ & $9(17.6 \%)$ & 0.036 \\
\hline 13 & 136 & $107(12.3 \%)$ & $22(12.3 \%)$ & $7(13.7 \%)$ & \\
\hline 14 & 164 & $127(14.6 \%)$ & $29(16.2)$ & $8(15.7 \%)$ & \\
\hline 15 & 177 & $127(14.6 \%)$ & $37(20.7 \%)$ & $13(25.5 \%)$ & \\
\hline 16 & 216 & $175(20.1 \%)$ & $35(19.6 \%)$ & $6(11.8 \%)$ & \\
\hline 17 & 180 & $157(18.0 \%)$ & $17(9.5 \%)$ & $6(11.8 \%)$ & \\
\hline 18 & 104 & $88(10.1 \%)$ & $14(7.8 \%)$ & $2(3.9 \%)$ & \\
\hline \multicolumn{6}{|l|}{ Gender } \\
\hline Boys & $537(48.8 \%)$ & $438(50.3 \%)$ & $74(41.3 \%)$ & $25(49 \%)$ & 0.09 \\
\hline Girls & $563(51.2 \%)$ & $432(49.7 \%)$ & $105(58.7 \%)$ & $26(51 \%)$ & \\
\hline \multicolumn{6}{|l|}{ Physical activity } \\
\hline Yes & $703(63.9 \%)$ & $556(63.9 \%)$ & $109(60.9 \%)$ & $38(74.5 \%)$ & $<0.0001$ \\
\hline No & $397(36.1 \%)$ & $314(36.1 \%)$ & $70(39.1 \%)$ & $13(25.5 \%)$ & \\
\hline \multicolumn{6}{|c|}{ Family history of obesity } \\
\hline Yes & $324(29.5 \%)$ & $217(24.9 \%)$ & $72(40.2 \%)$ & $35(68.6 \%)$ & $<0.0001$ \\
\hline No & $776(70.5 \%)$ & $653(74.9 \%)$ & $107(59.8 \%)$ & $16(31.4 \%)$ & \\
\hline \multicolumn{6}{|c|}{ Consumption of sweetened snacks } \\
\hline Yes & $794(72.2 \%)$ & $642(73.8 \%)$ & $123(68.7 \%)$ & $29(56.9 \%)$ & 0.009 \\
\hline No & $306(27.8 \%)$ & $228(26.2 \%)$ & $56(31.3 \%)$ & $22(43.1 \%)$ & \\
\hline $\mathrm{WC}(\mathrm{cm})$ & $\begin{array}{c}74.5 \pm 10.6 \\
1100\end{array}$ & $71.1 \pm 7.5$ & $83.8 \pm 9.3$ & $98.5 \pm 10.6$ & $<0.0001$ \\
\hline $\mathrm{HC}(\mathrm{cm})$ & $\begin{array}{c}89.6 \pm 10.3 \\
1100\end{array}$ & $87.1 \pm 8.5$ & $96.9 \pm 9.4$ & $107.6 \pm 10.2$ & $<0.0001$ \\
\hline $\mathrm{WC} / \mathrm{HC}$ & $\begin{array}{c}0.83 \pm 0.072 \\
1100\end{array}$ & $0.82 \pm 0.06$ & $0.87 \pm 0.80$ & $0.92 \pm 0.60$ & $<0.0001$ \\
\hline $\mathrm{SBP}(\mathrm{mmHg})$ & $\begin{array}{c}112 \pm 15 \\
1100\end{array}$ & $111 \pm 15$ & $113 \pm 14.7$ & $118 \pm 13$ & 0.001 \\
\hline DBP (mmHg) & $\begin{array}{c}67 \pm 11 \\
1100\end{array}$ & $66 \pm 11$ & $69 \pm 11$ & $70 \pm 12$ & $<0.0001$ \\
\hline $\mathrm{PP}(\mathrm{mmHg})$ & $\begin{array}{c}45 \pm 12 \\
1100\end{array}$ & $45 \pm 12$ & $44 \pm 12$ & $47 \pm 9$ & 0.29 \\
\hline FPG (mg/dl) & $\begin{array}{c}89 \pm 8 \\
987\end{array}$ & $89 \pm 9$ & $89 \pm 8$ & $89 \pm 7$ & 0.97 \\
\hline $\mathrm{FPG} \geq 100 \mathrm{mg} / \mathrm{dl}^{* *}$ & $86(8.7 \%)$ & $69(8.9 \%)$ & $16(10 \%)$ & $1(2 \%)$ & 0.21 \\
\hline $\mathrm{CT}(\mathrm{mg} / \mathrm{dl})$ & $\begin{array}{c}155 \pm 30 \\
979\end{array}$ & $153 \pm 29$ & $160 \pm 30$ & $154 \pm 33$ & 0.039 \\
\hline $\mathrm{TG}(\mathrm{mg} / \mathrm{dl})$ & $\begin{array}{c}73 \pm 30 \\
980\end{array}$ & $71 \pm 29$ & $84 \pm 33$ & $77 \pm 29$ & $<0.0001$ \\
\hline $\mathrm{TG} \geq 1,1 \mathrm{mg} / \mathrm{dl} * * *$ & $107(10.9 \%)$ & $71(9.2 \%)$ & $31(19.7 \%)$ & $5(10.2 \%)$ & 0.001 \\
\hline
\end{tabular}


Table 1

(Continued)

\begin{tabular}{|c|c|c|c|c|c|}
\hline Parameter & Total $^{*}$ & Normal weight & Overweight & Obese & $\mathrm{P}$ \\
\hline HDLc (mg/dl) & $\begin{array}{c}67 \pm 26 \\
965\end{array}$ & $67 \pm 25$ & $64 \pm 27$ & $72 \pm 29$ & 0.142 \\
\hline $\mathrm{HDLc} \leq 0,4 \mathrm{mg} / \mathrm{dl}^{* * *}$ & $90(9.3 \%)$ & $59(7.8 \%)$ & $27(17.3 \%)$ & $4(8.3 \%)$ & 0.001 \\
\hline LDLc (mg/dl) & $\begin{array}{c}73 \pm 33 \\
958\end{array}$ & $72 \pm 33$ & $79 \pm 36$ & $65 \pm 38$ & 0.026 \\
\hline Insulinemia $(\mu \mathrm{IU} / \mathrm{ml})$ & $\begin{array}{c}9.42 \pm 5.02 \\
141\end{array}$ & $7.97 \pm 3.59$ & $11.67 \pm 5.09$ & $13.60 \pm 8.22$ & $<0.0001$ \\
\hline HOMA & $\begin{array}{c}2.16 \pm 1.24 \\
131\end{array}$ & $\begin{array}{l}1.84 \pm 0.92 \\
89(67.9 \%)\end{array}$ & $\begin{array}{l}2.61 \pm 1.21 \\
30(22.9 \%)\end{array}$ & $\begin{array}{c}3.41 \pm 2.03 \\
12(9.2 \%)\end{array}$ & $<0.0001$ \\
\hline HOMA $>3$ & $25(19.1 \%)$ & $11(12.4 \%)$ & $9(30 \%)$ & $5(41.7 \%)$ & 0.012 \\
\hline
\end{tabular}

*Number of adolescents with data. Cut-offs for hyperglycemia and dyslipidemia in children and adolescents are based on International Diabetes Federation (IDF) criteria** and data from the North American National Cholesterol Education Program ${ }^{* * *}$ [24, 25]. The percentages are calculated in the different classes: obesity, overweight, normal weight. WC: waist circumference, HC: hip circumference, SBP: systolic blood pressure, DBP: diastolic blood pressure, PP: pulse pressure (calculated as the difference between systolic and diastolic blood pressure), FPG: fasting plasma glucose, TC: total cholesterol, HDL-c: high density lipoprotein cholesterol, LDL-c: low density lipoprotein cholesterol, TG: triglycerides, HOMA: Homeostasis Model Assessment for estimating insulin resistance, was calculated by the formula [Fasting insulin $(\mu \mathrm{IU} / \mathrm{mL}) \times$ Fasting plasma glucose $(\mathrm{g} / \mathrm{l}) \times 5.5] / 22.5$, IOTF : International ObesityTask Force, HDL-cholesterol: to convert mg/dl to mmol/1 divide by 38.67 . Triglycerides: to convert $\mathrm{mg} / \mathrm{dl}$ to $\mathrm{mmol} / \mathrm{l}$ divide by 88.5 . Glucose: to convert $\mathrm{mg} / \mathrm{dl}$ to mmol/l divide by 18.5 .

risk factor for obesity. This contributed to the propagation of the global obesity epidemics [27] and can predict a significant increase in the prevalence of obesity in Algeria in the future.

In this study, the number of obese and overweight girls was higher than the number of normal weight adolescents $(p=0.09)$. Adolescence is an important transition period starting from puberty. It is characterised by marked physiological and hormonal modifications both in males and females. During puberty, adipose tissue is increasingly stored in female breasts, hips and buttock areas, which is likely to account for the higher risk of excess weight during adolescence in females than in males [10, 17].

Adolescence is also an important milestone for the development and incidence of comorbidities associated with obesity in both males and females $[10,17,25,41]$. SBP and DBP are higher in overweight and obese adolescents compared to normal weight adolescents $(p=0.001$ and $<0.0001$ respectively) suggesting that BMI is a risk factor that increased $\mathrm{BP}[8,42,43]$.

Overall, we identified more metabolic abnormalities in overweight than obese adolescents compared to a French study [44], although the overweight population in our study may be considered as obese in other studies that did not use IOTF definitions. These differences may be explained by the effect of genetic susceptibility or the protecting role of fat deposition in subcutaneous tissues [15].

Furthermore, the HOMA index was higher and insulin resistance (defined by a HOMA index $\geq 3$ ) more prevalent in overweight and obese adolescents compared to normal weight adolescents, which indicates the role of excess weight in the development of IR. Several metabolic and cardiovascular complications of obesity can occur during childhood. They result mostly from IR and hyperinsulinemia which are the most common abnormalities of obesity $[8,9,11,12,15,25]$. Other studies have identified a correlation between increased BMI and several components of the metabolic syndrome (MetS) $[9,15]$.

Obesity is associated with serious health outcomes during childhood and adolescence including mortality and morbidity at the adult age [2,9-12, 17, 45]. Also, 80\% of obese children remained obese at the adult age [9]. Over half of obese children aged 6 years old and 70-80\% of children aged over 10 years old remained obese at the adult age, compared to only $10 \%$ of children of the same age with normal weight becoming obese at the adult 
age. This risk is increased if there is a family history of obesity [10, 12]. Obesity in childhood also increases the risk of developing cardiovascular diseases and diabetes type 2 (DM2) at the adult age. An important Danish study with a long follow-up period of a cohort including over 14000 adult men and women with a known BMI at the age of 7-13 years, demonstrated a linear relationship between BMI during childhood and the risk of coronary heart disease at the adult age [16].

The MetS is also a major risk factor for the future development of DM2. In a study by Caprio, a population of 102 obese children and adolescents with MetS showed that 31 children had glucose intolerance during initial blood tests. After a follow-up period of 21 months, several emerging results were noted: in $1 / 3$ of cases, glucose tolerance was normalised and 1/3 of cases developed DM2. The most important risk predictors for the development of DM2 in this population were the significant increase in body weight, insulin resistance and the decrease in the first phase of insulin secretion at initial blood tests [9].

The current study has some strengths: the large size of the sample and the standardised measurement of anthropometric measurements, and the biochemical measurements performed in a central laboratory. However, some limitations should be acknowledged. The study was conducted in the city of Constantine, therefore it is not fully representative of all Algerian adolescents, as it did not include those living in rural areas and those no longer in school. In addition, HOMA index was determined in a limited part of the sample.

\section{Conclusion}

Obesity and overweight are alarming health risk issues that affect younger populations in developing countries and increasing mortality and morbidity at an early age. Therefore, it is essential to establish an effective healthcare strategy at a young age for the primary prevention of future complications.

\section{Acknowledgements}

Mr Abdelghani Letreche, statistician at the "Office Nationale de Statistiques" for his assistance with our survey, Dr Jacques Pariès for statistical analysis, Dr Karima Benmebarek, Moufida Benletreche and Pr. Chérifa Benletreche for blood test analysis, in addition to all the participating doctors, and the adolescents and their parents for consenting to participate in this study.

\section{Funding}

Dr Benmohammed's work has been funded by the Algerian Ministry of Higher Education and Scientific Research (Scholarship).

\section{Disclosure statement}

The authors declare that they have no conflict of interest.

\section{References}

[1] WHO. Obesity and overweight 2016 [updated June 2016. Available from: http://www.who.int/mediacentre/factsheets/fs311/en/. 
[2] Ng M, Fleming T, Robinson M, Thomson B, Graetz N, Margono C, et al. Global, regional, and national prevalence of overweight and obesity in children and adults during 1980-2013: A systematic analysis for the Global Burden of Disease Study 2013. Lancet (London, England). 2014;384(9945):766-81.

[3] Kelishadi R. Childhood overweight, obesity, and the metabolic syndrome in developing countries. Epidemiologic Reviews. 2007;29: 62-76.

[4] Misra A, Khurana L. Obesity and the metabolic syndrome in developing countries. The Journal of Clinical Endocrinology and Metabolism. 2008;93(11 Suppl 1):S9-30.

[5] Poobalan A, Aucott L. Obesity Among Young Adults in Developing Countries: A Systematic Overview. Current Obesity Reports. 2016;5(1):2-13

[6] Kumar S, Kelly AS. Review of Childhood Obesity: From Epidemiology, Etiology, and Comorbidities to Clinical Assessment and Treatment. Mayo Clinic Proceedings. 2017;92(2):251-65.

[7] Bastien M, Poirier P, Lemieux I, Despres JP. Overview of epidemiology and contribution of obesity to cardiovascular disease. Progress in Cardiovascular Diseases. 2014;56(4):369-81.

[8] Benmohammed K, Nguyen MT, Khensal S, Valensi P, Lezzar A. Arterial hypertension in overweight and obese Algerian adolescents: Role of abdominal adiposity. Diabetes \& Metabolism. 2011;37(4):291-7.

[9] Cali AM, Caprio S. Obesity in children and adolescents. The Journal of Clinical Endocrinology and Metabolism. 2008;93(11 Suppl 1): S31-6.

[10] Daniels SR, Arnett DK, Eckel RH, Gidding SS, Hayman LL, Kumanyika S, et al. Overweight in children and adolescents: Pathophysiology, consequences, prevention, and treatment. Circulation. 2005;111(15):1999-2012.

[11] Jolliffe CJ, Janssen I. Vascular risks and management of obesity in children and adolescents. Vascular Health and Risk Management. 2006;2(2):171-87.

[12] Levy-Marchal C, Arslanian S, Cutfield W, Sinaiko A, Druet C, Marcovecchio ML, et al. Insulin resistance in children: Consensus, perspective, and future directions. The Journal of Clinical Endocrinology and Metabolism. 2010;95(12):5189-98.

[13] Reilly JJ, Kelly J. Long-term impact of overweight and obesity in childhood and adolescence on morbidity and premature mortality in adulthood: Systematic review. International Journal of Obesity (2005). 2011;35(7):891-8.

[14] Styne DM, Arslanian SA, Connor EL, Farooqi IS, Murad MH, Silverstein JH, et al. Pediatric Obesity-Assessment, Treatment, and Prevention: An Endocrine Society Clinical Practice Guideline. The Journal of Clinical Endocrinology and Metabolism. 2017;102(3):709-57.

[15] Cali AM, Caprio S. Ectopic fat deposition and the metabolic syndrome in obese children and adolescents. Hormone Research. 2009;71(Suppl 1):2-7.

[16] Baker JL, Olsen LW, Sorensen TI. Childhood body-mass index and the risk of coronary heart disease in adulthood. The New England Journal of Medicine. 2007;357(23):2329-37.

[17] Biro FM, Wien M. Childhood obesity and adult morbidities. The American Journal of Clinical Nutrition. 2010;91(5):1499s-505s.

[18] Sonntag D, Ali S, Lehnert T, Konnopka A, Riedel-Heller S, Konig HH. Estimating the lifetime cost of childhood obesity in Germany: Results of a Markov Model. Pediatric Obesity. 2015;10(6):416-22.

[19] Global Strategy on Diet, Physical Activity and Health. WHO. http://www.who.int/dietphysicalactivity/factsheet_young_people/en/. Download August 2017.

[20] Cole TJ, Bellizzi MC, Flegal KM, Dietz WH. Establishing a standard definition for child overweight and obesity worldwide: International survey. BMJ (Clinical research ed). 2000;320(7244):1240-3.

[21] Lohman TG RA, Martorell R. Anthropometric Standardization Reference Manual. Champaign, Ill: Human Kinetics Publishers;1988.

[22] The fourth report on the diagnosis, evaluation, and treatment of high blood pressure in children and adolescents. Pediatrics. 2004;114(2 Suppl 4th Report):555-76.

[23] Benmohammed K, Valensi P, Balkau B, Lezzar A. Metabolic syndrome in adolescents: Definition based on regression of IDF adult cut-off points. Public Health. 2016;141:88-94.

[24] Daniels SR, Greer FR. Lipid screening and cardiovascular health in childhood. Pediatrics. 2008;122(1):198-208

[25] Zimmet P, Alberti G, Kaufman F, Tajima N, Silink M, Arslanian S, et al. The metabolic syndrome in children and adolescents. Lancet (London, England). 2007;369(9579):2059-61.

[26] Matthews DR, Hosker JP, Rudenski AS, Naylor BA, Treacher DF, Turner RC. Homeostasis model assessment: Insulin resistance and beta-cell function from fasting plasma glucose and insulin concentrations in man. Diabetologia. 1985;28(7):412-9.

[27] Levy E, Saenger A, Steffes M, Delvin E. Pediatric obesity and cardiometabolic disorders: Risk factors and biomarkers. EJIFCC. 2017;28(1):6.

[28] Miller WG, Thienpont LM, Van Uytfanghe K, Clark PM, Lindstedt P, Nilsson G, et al. Toward standardization of insulin immunoassays Clinical Chemistry. 2009;55(5):1011-8. 
[29] Wallace TM, Levy JC, Matthews DR. Use and abuse of HOMA modeling. Diabetes Care. 2004;27(6):1487-95.

[30] Yin J, Li M, Xu L, Wang Y, Cheng H, Zhao X, et al. Insulin resistance determined by Homeostasis Model Assessment (HOMA) and associations with metabolic syndrome among Chinese children and teenagers. Diabetology \& Metabolic Syndrome. 2013;5(1):71.

[31] Grossman DC, Bibbins-Domingo K, Curry SJ, Barry MJ, Davidson KW, Doubeni CA, et al. Screening for Obesity in Children and Adolescents: US Preventive Services Task Force Recommendation Statement. Jama. 2017;317(23):2417-26.

[32] Guerrero AD, Mao C, Fuller B, Bridges M, Franke T, Kuo AA. Racial and Ethnic Disparities in Early Childhood Obesity: Growth Trajectories in Body Mass Index. Journal of Racial and Ethnic Health Disparities. 2016;3(1):129-37.

[33] Pedersen DC, Aarestrup J, Pearson S, Baker JL. Ethnic Inequalities in Overweight and Obesity Prevalence among Copenhagen Schoolchildren from 2002 to 2007. Obesity Facts. 2016;9(4):284-95.

[34] Aounallah-Skhiri H, Traissac P, El Ati J, Eymard-Duvernay S, Landais E, Achour N, et al. Nutrition transition among adolescents of a south-Mediterranean country: Dietary patterns, association with socio-economic factors, overweight and blood pressure. A crosssectional study in Tunisia. Nutrition Journal. 2011;10(1):38.

[35] Blouza-Chabchoub S, Rached-Amrouche C, Jamoussi-Kammoun H, Bouchaa N. Frequency and risk factors of obesity in Tunisian adolescent. La Tunisie Medicale. 2006;84(11):714-6.

[36] Fredriks AM, Van Buuren S, Sing RA, Wit JM, Verloove-Vanhorick SP. Alarming prevalences of overweight and obesity for children of Turkish, Moroccan and Dutch origin in The Netherlands according to international standards. Acta Paediatrica (Oslo, Norway: 1992). 2005;94(4):496-8.

[37] Gupta N, Goel K, Shah P, Misra A. Childhood obesity in developing countries: Epidemiology, determinants, and prevention. Endocrine Reviews. 2012;33(1):48-70.

[38] Han JC, Lawlor DA, Kimm SY. Childhood obesity. Lancet (London, England). 2010;375(9727):1737-48.

[39] Rovillé-Sausse F. Évolution en 20 ans de la corpulence des enfants de 0 à 4 ans issus de l'immigration maghrébine. Revue d'épidémiologie et de santé publique. 1999;47(1):37-44.

[40] Lynch J, Wang XL, Wilcken DE. Body mass index in Australian children: Recent changes and relevance of ethnicity. Archives of Disease in Childhood. 2000;82(1):16-20.

[41] van Vliet M, Heymans MW, von Rosenstiel IA, Brandjes DP, Beijnen JH, Diamant M. Cardiometabolic risk variables in overweight and obese children: A worldwide comparison. Cardiovascular Diabetology. 2011;10:106.

[42] Aounallah-Skhiri H, El Ati J, Traissac P, Ben Romdhane H, Eymard-Duvernay S, Delpeuch F, et al. Blood pressure and associated factors in a North African adolescent population. a national cross-sectional study in Tunisia. BMC Public Health. 2012;12:98.

[43] Weiss R, Dziura J, Burgert TS, Tamborlane WV, Taksali SE, Yeckel CW, et al. Obesity and the metabolic syndrome in children and adolescents. The New England Journal of Medicine. 2004;350(23):2362-74.

[44] de Gennes J-L, Benlian P, Dreux C, Pelegrin P, editors. Dépistage des anomalies sanguines glucidolipidiques à risque coronarien, de 16 à 19-20 ans. À propos d'une enquête menée chez 599 jeunes volontaires. Annales d'Endocrinologie; 2007: Elsevier.

[45] Freedman DS, Khan LK, Serdula MK, Dietz WH, Srinivasan SR, Berenson GS. Racial differences in the tracking of childhood BMI to adulthood. Obesity Research. 2005;13(5):928-35. 